\title{
Genotype-specific prevalence of human papillomavirus infection in asymptomatic Peruvian women: a community-based study
}

\author{
Juana del Valle-Mendoza ${ }^{1,2^{*}}$ (0), Lorena Becerra-Goicochea ${ }^{3 \dagger}$, Miguel Angel Aguilar-Luis ${ }^{1,2}$, \\ Luis Pinillos-Vilca ${ }^{3}$, Hugo Carrillo-Ng 1,2, Wilmer Silva-Caso ${ }^{1,2}$, Carlos Palomares-Reyes ${ }^{1}$, \\ Andre-Alonso Taco-Masias ${ }^{1}$, Ronald Aquino-Ortega ${ }^{1,2}$, Carmen Tinco-Valdez ${ }^{1,2}$, Yordi Tarazona-Castro ${ }^{2,4}$, \\ Cynthia-Wendy Sarmiento-Ramirez ${ }^{2}$ and Luis J. del Valle 5* $^{*}$
}

\begin{abstract}
Objective: To determine the general and genotype-specific prevalence of HPV and to identify potential risk factors for the infection in a population-based screening of Peruvian women.

Results: A total of 524 samples were analyzed by PCR and a total of $100 \mathrm{HPV}$ positive samples were found, of which 89 were high-risk, 19 were probably oncogenic, 9 were low-risk and 27 other HPV types. The 26-35 and 36-45 age groups showed the highest proportion of HPV positive samples with a total of 37\% (37/100) and 30\% (30/100), respectively. Moreover, high-risk HPV was found in $33.7 \%$ of both groups and probably oncogenic HPV in $52.6 \%$ and $31.6 \%$, respectively. High-risk HPV were the most frequent types identified in the population studied, being HPV-52, HPV-31 and HPV-16 the most commonly detected with $17.6 \%, 15.7 \%$ y $12.9 \%$, respectively. Demographic characteristics and habits were assessed in the studied population. A total of $62 \%$ high-risk HPV were detected in married/ cohabiting women. Women with two children showed the highest proportion (33.8\%) of high-risk HPV, followed by women with only one child (26.9\%). Those women without history of abortion had a higher frequency of high-risk HPV (71.9\%), followed by those with one abortion (25.8\%).
\end{abstract}

Keywords: Peru, Human papillomavirus, Cervical cancer, PCR

\section{Introduction}

The human papillomavirus (HPV) is a double stranded DNA virus, with worldwide distribution [1,2]. More than 100 types of human papillomavirus have been identified, including 13 high-risk types, which are responsible for

\footnotetext{
*Correspondence: juana.delvalle@upc.pe; luis.javier.del.valle@upc.edu ${ }^{\dagger} J$ uana del Valle-Mendoza and Lorena Becerra-Goicochea contributed equally to this article

1 School of Medicine, Research and Innovation Center of the Faculty of Health Sciences, Universidad Peruana de Ciencias Aplicadas, Lima, Peru

${ }^{5}$ Barcelona Research Center for Multiscale Science and Engineering, Departament D'Enginyeria Química, EEBE, Universitat Politècnica de Catalunya (UPC), Barcelona, Spain

Full list of author information is available at the end of the article
}

cervical, anogenital and oropharyngeal cancers [2-4]. $\mathrm{HPV}$ infection is the most common sexually transmitted infection worldwide, that affects at least $50 \%$ of sexually active individuals of both sexes at some point during their life $[2,3]$. The prevalence of HPV infection peaks in young sexually active women and decreases after 35 years of age, however, a small second peak occurs in middleaged women older than 55 years in some developing regions $[5,6]$.

It has been reported that viral infections contribute to $15-20 \%$ of all human cancers, as several viruses facilitate the multistage development of cancers [1]. Most HPV infections are harmless and clear spontaneously within

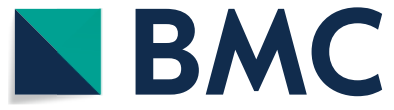

(c) The Author(s) 2021. This article is licensed under a Creative Commons Attribution 4.0 International License, which permits use, sharing, adaptation, distribution and reproduction in any medium or format, as long as you give appropriate credit to the original author(s) and the source, provide a link to the Creative Commons licence, and indicate if changes were made. The images or other third party material in this article are included in the article's Creative Commons licence, unless indicated otherwise in a credit line to the material. If material is not included in the article's Creative Commons licence and your intended use is not permitted by statutory regulation or exceeds the permitted use, you will need to obtain permission directly from the copyright holder. To view a copy of this licence, visit http://creativeco mmons.org/licenses/by/4.0/. The Creative Commons Public Domain Dedication waiver (http://creativecommons.org/publicdomain/ zero/1.0/) applies to the data made available in this article, unless otherwise stated in a credit line to the data. 
1-2 years of acquiring it; however, persistent infection with high-risk HPV can lead to cancer [1-3]. HPV 16 and 18 are the most common high-risk types, which are involved in around $70 \%$ of all cervical cancer [2]. Cervical cancer is the fourth most common cancer in women in the world, with an incidence rate of 13.1 per 100,000 women/year and nearly half a million of cases yearly [7]. Currently, developing regions such as Latin America have higher rates of cervical cancer, with incidence rates ranging from 10 to 80 per 100,000 women/year [8].

Cervical screening and early treatment have successfully lowered cervical cancer incidence and mortality in developed countries, nonetheless, these measures have not been as effective in Peru $[9,10]$. HPV infection and cervical cancer remain a major public health problem in Peru, being the second most common cancer among women and affecting 32 per 100,000 women/year [10, $11]$.

Since the recent introduction of molecular techniques for detection of HPV, it has become evident that screening with HPV tests protect better against future cancerous lesions than cytology-based screening alone, and consequently, virological screening programs are becoming increasingly recommended [12-14]. It is crucial recognize the epidemiology of HPV in a certain population to provide a better control of the disease, therefore, the objective of this study was to determine the general and genotype-specific prevalence of HPV and to identify potential risk factors for the infection in a populationbased screening of Peruvian women.

\section{Main text \\ Methods \\ Patients and study design}

A cross sectional study was carried out, using samples and data collected from a previous study performed in Hospital Regional Docente de Cajamarca, in northern Peru during September 2017 to July 2019. Asymptomatic women attending a gynecological outpatient health center, who had a history of at least 1 sexual encounter were studied. Exclusion criteria included: pregnancy, severe gynecological bleeding, previous hysterectomy, previous history of HPV-related disease including cancer, warts and cutaneous manifestations.

\section{Sample collection}

Samples were collected from the ectocervix and endocervix using a disposable cytobrush, they were stored in a tube containing phosphate buffered saline $(\mathrm{pH}: 8.6)$ for preservation. Three aliquots of each sample were stored at $-20^{\circ} \mathrm{C}$ until testing.

\section{DNA extraction}

Samples were kept at $-20{ }^{\circ} \mathrm{C}$ until analyzed. DNA extraction from $200 \mu \mathrm{L}$ of cervico-vaginal samples was performed using the High Pure PCR Viral Nucleic Acid Kit (Roche Diagnostics GmbH, Mannheim, Germany), according to manufacturer's instructions.

\section{PCR for HPV amplification}

HPV amplification was carried out using primers and conditions previously described [15]. The HPV genotypes were classified based on the IARC classification for cancer risk: high, possibly oncogenic and low risk [4].

\section{Ethics statement}

This study was approved by the Research Ethics Board of the Hospital Regional de Cajamarca, Peru. The samples were obtained in the Specialized Oncological Preventive Service of the Hospital Regional de Cajamarca, as part of the cervical cancer screening program. All samples were analyzed after a written informed consent was signed.

\section{Statistical analysis}

All analyses were processed with the IBM Statistical Package for the Social Sciences (SPSS) software version 21.0 (SPSS, Chicago, IL, USA).

Maps were created using QGIS 3.12.3 software. Data for creating the map were acquired from the Instituto Nacional de Estadística e Informática (https://www. inei.gob.pe/).

\section{Results}

A total of 524 samples were analyzed by PCR, which were classified according to its oncogenic potential in 13 high-risk HPV, 12 probably oncogenic HPV and 2 low-risk HPV (Additional file 1: Table S1) The population studied was analyzed according to age groups, the most common group was between $36-45$ years old with $35.1 \%$ (184/524), followed by $26-35$ years old with $31.9 \%$ (167/524). A total of 100 patients positive for HPV were found, of which 89 were high-risk, 19 were probably oncogenic, 9 were low-risk and 27 other HPV types. The 26-35 and 36-45 age groups showed the highest proportion of HPV positive samples with a total of 37\% (37/100) and 30\% (30/100), respectively. Moreover, high-risk HPV was found in $33.7 \%$ of both groups and probably oncogenic HPV in $52.6 \%$ and $31.6 \%$, respectively (Table 1 ).

High-risk HPV were the most frequent types identified in the population studied, being HPV-52, HPV-31 and HPV-16 the most commonly detected with $17.6 \%$, 
Table 1 Demographics in patients Human papillomavirus (HPV) positive

\begin{tabular}{|c|c|c|c|c|c|c|}
\hline \multirow[t]{2}{*}{ Age range } & \multirow{2}{*}{$\begin{array}{l}\text { Totality } \\
n=524(\%)\end{array}$} & \multirow{2}{*}{$\begin{array}{l}\text { HPV positives } \\
n=100 \text { (\%) }\end{array}$} & \multicolumn{4}{|l|}{ Genotype HPV } \\
\hline & & & High risk $n=89$ & $\begin{array}{l}\text { Probably } \\
\text { oncogenic } n=19\end{array}$ & Low risk $\mathrm{n}=9$ & $\begin{array}{l}\text { Other HPV } \\
\text { types } n=27\end{array}$ \\
\hline$\leq 25$ & $48(9.2)$ & $16(16.0)$ & $10(11.2)$ & $1(5.3)$ & $1(11.1)$ & $9(33.3)$ \\
\hline $26-35$ & 167 (31.9) & $37(37.0)$ & $30(33.7)$ & $10(52.6)$ & $6(66.7)$ & $5(18.5)$ \\
\hline $36-45$ & $184(35.1)$ & $30(30.0)$ & $30(33.7)$ & $6(31.6)$ & $2(22.2)$ & $8(29.6)$ \\
\hline$\geq 46$ & $125(23.9)$ & $17(17.0)$ & $19(21.4)$ & $2(10.5)$ & $0(0.0)$ & $5(18.6)$ \\
\hline Total & $524(100.0)$ & $100(100.0)$ & 89 (100.0) & $19(100.0)$ & $9(100.0)$ & $27(100.0)$ \\
\hline
\end{tabular}

*HPV genotypes: High risk: 16, 18, 31, 33, 35, 39, 45, 51, 52, 56, 58, 59, 68. Probably oncogenic: $26,30,34,53,66,67,69,70,73,82,85,97$. Low risk: 6, 11

$15.7 \%$ and $12.9 \%$, respectively. Followed by types HPV91 with 14.8\%, HPV-71, HPV-43 and HPV-40 with $11.1 \%$, which have not been classified according to its oncogenic potential. Also, probably oncogenic types such as HPV-97, HPV-85, HPV-73 and HPV-34 were not detected in the current study. Finally, HPV-18, another important oncogenic type, was only identified in one sample among all the positive women (Additional file 1: Table S2) (Fig. 1).
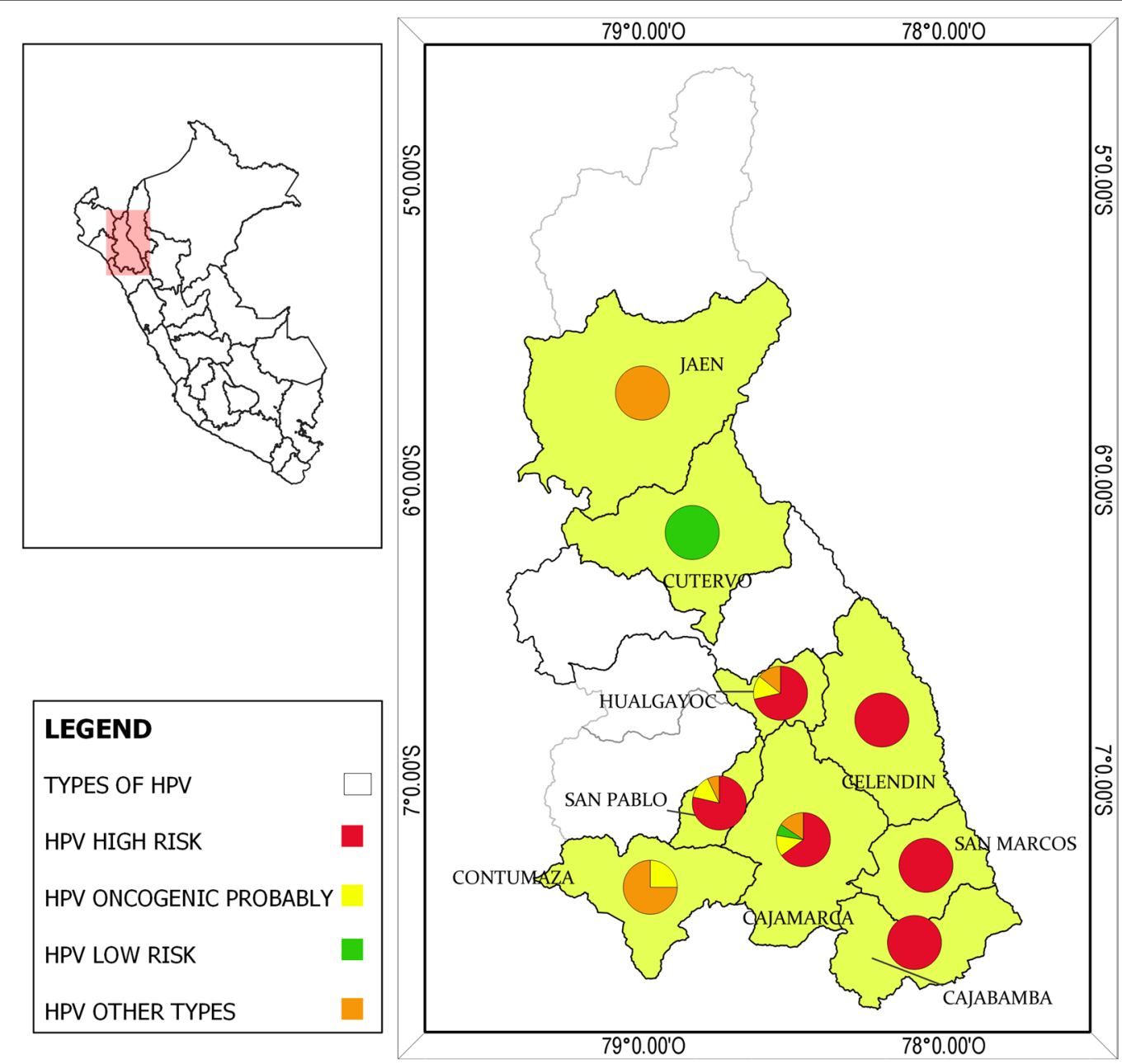

Fig. 1 Geographic distribution of infection of HPV in Cajamarca-Peru. Map created by authors using QGIS3.12.3 software 
Demographic characteristics and habits were assessed in the studied population. A total of $62 \%$ highrisk HPV were detected in married/cohabiting women. Women with two or more sexual partners showed a
63\% of HPV detection, among these, women who had a sexual partner in the last 6 months showed a frequency of $83 \%$ of high-risk HPV. Also, of the total of

Table 2 Demographic characteristics and habits in the studied population

\begin{tabular}{|c|c|c|c|c|c|c|}
\hline \multirow[t]{2}{*}{ Characteristic } & \multirow{2}{*}{$\begin{array}{l}\text { Totality of cases } \\
n=524(\%)\end{array}$} & \multirow{2}{*}{$\begin{array}{l}\text { HPV positives } \\
n=100(\%)\end{array}$} & \multicolumn{4}{|c|}{ HPV types detected } \\
\hline & & & $\begin{array}{l}\text { High risk } \\
n=89(\%)\end{array}$ & $\begin{array}{l}\text { Probably } \\
\text { oncogenic } \\
n=19(\%)\end{array}$ & $\begin{array}{l}\text { Low risk } \\
n=9(\%)\end{array}$ & $\begin{array}{l}\text { Other HPV types } \\
n=27(\%)\end{array}$ \\
\hline \multicolumn{7}{|l|}{ Marital status } \\
\hline Married/cohabiting & $388(74.0)$ & $64(64.0)$ & $62(69.7)$ & $15(79.0)$ & $5(55.6)$ & $10(37.0)$ \\
\hline $\begin{array}{l}\text { Single/separated/ } \\
\text { divorced/widowed }\end{array}$ & $136(26.0)$ & $36(36.0)$ & $27(30.3)$ & $4(21.0)$ & $4(44.4)$ & $17(63.0)$ \\
\hline \multicolumn{7}{|c|}{ Number of sexual partners lifetime } \\
\hline 0 & $0(0.0)$ & $0(0.0)$ & $0(0.0)$ & $0(0.0)$ & $0(0.0)$ & $0(0.0)$ \\
\hline 1 & $259(49.4)$ & $37(37.0)$ & $37(41.6)$ & $6(31.6)$ & $1(11.1)$ & $7(26.0)$ \\
\hline 2 & $177(33.8)$ & $40(40.0)$ & $36(40.4)$ & $8(42.1)$ & $2(22.2)$ & $11(40.7)$ \\
\hline$\geq 3$ & $88(16.8)$ & $23(23.0)$ & $16(18.0)$ & $5(26.3)$ & $6(66.7)$ & $9(33.3)$ \\
\hline \multicolumn{7}{|c|}{ Number of sexual partners in the last 6 months } \\
\hline 0 & $61(11.6)$ & $9(9.0)$ & $6(6.7)$ & $1(5.3)$ & $2(22.2)$ & $6(22.2)$ \\
\hline 1 & 459 (87.6) & $91(91.0)$ & $83(93.3)$ & $18(94.7)$ & $7(77.8)$ & $21(77.8)$ \\
\hline$\geq 2$ & $4(0.8)$ & $0(0.0)$ & $0(0.0)$ & $0(0.0)$ & $0(0.0)$ & $0(0.0)$ \\
\hline \multicolumn{7}{|l|}{ Use of condom } \\
\hline Yes & $109(20.8)$ & $23(23.0)$ & $14(15.7)$ & $5(26.3)$ & $2(22.2)$ & $11(40.7)$ \\
\hline No & $415(79.2)$ & $77(77.0)$ & $75(84.3)$ & $14(73.7)$ & $7(77.8)$ & $16(59.3)$ \\
\hline \multicolumn{7}{|l|}{ Use of sex toys } \\
\hline Yes & $2(0.4)$ & $0(0.0)$ & $0(0.0)$ & $0(0.0)$ & $0(0.0)$ & $0(0.0)$ \\
\hline No & $522(99.6)$ & $100(100.0)$ & $89(100.0)$ & $19(100.0)$ & $9(100.0)$ & $27(100.0)$ \\
\hline \multicolumn{7}{|l|}{ Extramarital affairs } \\
\hline Yes & $31(5.9)$ & $8(8.0)$ & $6(6.7)$ & $2(10.5)$ & $0(0.0)$ & $1(3.7)$ \\
\hline No & $493(94.1)$ & $92(92.0)$ & $83(93.3)$ & $17(89.5)$ & $9(100.0)$ & $26(96.3)$ \\
\hline \multicolumn{7}{|l|}{ Victim of sexual abuse } \\
\hline Yes & $24(4.6)$ & $6(6.0)$ & $8(9.0)$ & $3(15.78)$ & $0(0.0)$ & $0(0.0)$ \\
\hline No & $500(95.4)$ & $94(94.0)$ & $81(91.0)$ & $16(84.2)$ & $9(100.0)$ & $27(100.0)$ \\
\hline \multicolumn{7}{|c|}{ Date of the last papanicolaou test } \\
\hline Never in life & $78(14.9)$ & $11(11.0)$ & $18(20.2)$ & $0(0.00)$ & $2(22.22)$ & $7(26.0)$ \\
\hline$\leq 1$ year & $238(45.4)$ & $56(56.0)$ & $40(44.9)$ & $5(26.32)$ & $6(66.67)$ & $12(44.4)$ \\
\hline$\geq 2$ years & $208(39.7)$ & $33(33.0)$ & $31(34.8)$ & $14(73.68)$ & $1(11.11)$ & $8(29.6)$ \\
\hline \multicolumn{7}{|l|}{ Number of births } \\
\hline 0 & $53(10.11)$ & $17(17.0)$ & $9(10.1)$ & $3(15.79)$ & $5(55.56)$ & $10(37.0)$ \\
\hline 1 & $107(20.42)$ & $28(28.0)$ & $24(27.0)$ & $3(15.79)$ & $2(22.22)$ & $7(26.0)$ \\
\hline 2 & $155(29.58)$ & $32(32.0)$ & $30(33.7)$ & $12(63.16)$ & $1(11.11)$ & $5(18.5)$ \\
\hline 3 & $115(21.95)$ & $13(13.0)$ & $14(15.7)$ & $1(5.26)$ & $0(0.00)$ & $5(18.5)$ \\
\hline 4 & $51(9.73)$ & $2(2.0)$ & $3(3.3)$ & $0(0.00)$ & $0(0.00)$ & $0(0.0)$ \\
\hline$\geq 5$ & $43(8.2)$ & $8(8.0)$ & $9(10.1)$ & $0(0.0)$ & $1(11.1)$ & $0(0.0)$ \\
\hline \multicolumn{7}{|l|}{ Number of abortions } \\
\hline 0 & $373(71.2)$ & $73(73.0)$ & $64(71.9)$ & $17(89.5)$ & $9(100.0)$ & $13(48.1)$ \\
\hline 1 & $121(23.1)$ & $24(24.0)$ & $23(25.8)$ & $0(0.0)$ & $0(0.0)$ & $13(48.1)$ \\
\hline 2 & $25(4.8)$ & $2(2.0)$ & $0(0.0)$ & $2(10.5)$ & $0(0.0)$ & $1(3.8)$ \\
\hline 3 & $5(1.0)$ & $1(1.0)$ & $2(2.2)$ & $0(0.0)$ & $0(0.0)$ & $0(0.0)$ \\
\hline
\end{tabular}


HPV positive women a 77\% did not report condom use, being $75 \%$ positive for high-risk HPV (Table 2).

Women with two children showed the highest proportion (33.7\%) of high-risk HPV, followed by women with only one child (26.9\%). Those women without history of abortion had a higher frequency of high-risk HPV (71.9\%), followed by those with one abortion (25.8\%). History of sexual abuse and extramarital affairs did not show a high frequency of HPV detection. Finally, $56 \%$ of women that underwent Pap test within one year or less were positive for HPV, with $44.9 \%$ presenting high-risk types (Table 2).

\section{Discussion}

The understanding that persistent infection with highrisk HPV is crucial for the pathogenesis of cervical cancer has led to new approaches for primary and secondary prevention [12]. Vaccines targeting HPV16 and HPV18, the two most common oncogenic types, were introduced years ago; however, despite vaccination, early screening remains the most significant method to decrease deaths attributable to cervical cancer [12, 16]. Developed countries have shown that cervical cancer rates can decrease with cytology-based primary screening; however, these programs have been difficult to implement in resourcelimited countries [17]. HPV testing has a high sensitivity and negative predictive value; therefore, it identifies women at higher risk of cervical cancer, which can be treated with a more specific protocol [16, 17]. Moreover, HPV testing can be used for epidemiological studies, as HPV prevalence from a specific region measures the general risk for developing cervical cancer in that territory $[18,19]$.

In the present study, we determined the general and genotype-specific prevalence of HPV in a populationbased screening of asymptomatic women in Cajamarca, Peru. This epidemiological information and potential predictors of infection are crucial to evaluate vaccination and achieve cervical cancer control in the region.

Firstly, we could highlight the significant prevalence (19.1\%) found in the study, which is higher than global pooled prevalence of $11 \%$ according to two meta-analyses $[19,20]$. Moreover, the prevalence in this study peaks in young women of reproductive age, which is similar to previous literature $[5,6,20]$. For example, Steben et al. [21] reported that detection of HPV was higher among women aged $20-24$ years old with a $44.8 \%$ of the total cases. Although, it has been recognized that regions like Latin America show a second peak in middle-aged women of around 55 years old $[6,20]$, the present study showed a decline in the prevalence of women aged 46 or older.
Regarding specific genotypes, this study found that types 52, 16 and 31 were the most frequent high-risk HPV, with $17.6 \%, 15.7 \%$ and $12.9 \%$, respectively. Conversely, type 18 was only found in one sample. According to literature, HPV-16 and HPV-18 are associated with approximately $70 \%$ of all cervical cancers [2], moreover, both genotypes have been the most commonly detected in women with normal cytology [6, 20]. A systematic review revealed that the most common HPV types identified were HPV-16 (9.5\%), HPV-18 (6.2\%) and HPV-33,52 and $58(0.3 \%)$ [22]. The findings in the present study are not consistent with previous estimates, although HPV prevalence is highly variable according to the territory, we should emphasize the high prevalence of HPV-52 and 31 among the samples studied.

HPV infection was also evaluated according to some characteristics of the population to identify potential predictors for infection. We could highlight the greater prevalence among married and cohabiting women, which differs from a study carried out by Castellague [23] that found a higher occurrence of HPV in divorced women. Regarding the number of sexual partners, previous literature evidenced that women with 5 or more sexual partners had the highest proportion of cases with $67 \%$, followed by women with 2-4 sexual partners [23, 24]. This differs from our findings in which women with 1 and 2 sexual partners had higher prevalence than those with 3 or more partners, moreover most of these infections were with high-risk types.

Sexual behavior and habits are important determinants for HPV infection, as infection is most commonly acquired sexually. One of the most important factors that may have an effect on HPV transmission is condom use. A study carried out by Winer et al. [25] showed a low probability of infection with high-risk genotypes among women whose partner consistently used condom in the last eight months. Improper use of condom has also been associated with a higher risk for acquiring HPV infection, nearly doubling the risk of infection compared to correct use [18]. Our data show that women whose partners did not use condom had a higher detection of HPV and highrisk genotypes (89\%). Data regarding condom use and its protective role on HPV infection remains inconsistent, however appropriate use of this tool may reduce transmission [25-27].

Another habit evaluated was the use of sexual toys, a previous study on university women showed that these devices are used in approximately $65 \%$ of sexual encounters [28], moreover HPV was identified in $75 \%$ of women who reported use of vibrators. In the present study, only a $2 \%$ of the total population reported use of sexual toys and no cases of infection was detected. Finally, in this study less than $50 \%$ of women enrolled did not undergo 
a Papanicolau (Pap) smear during the last year, being this group of women the one with the highest prevalence of high-risk HPV. This finding differs from the current guidelines by different international and national organizations that recommend screening with Pap smear and/ or HPV testing depending on the age and risk factors [29-32].

In conclusion a high prevalence was found among Peruvian women, being the ones between $26-35$ yearsold and those married/cohabiting the most commonly affected. Also, it was observed a high frequency of highrisk HPV, being types 52, 16 and 31 the most commonly identified. This study highlights the importance to detect the general and genotype-specific prevalence in different populations, as these are important epidemiological tools. Screening with cytological and molecular methods are recommended particularly in women with risk factors.

\section{Limitations}

Firstly, an important limitation is that other sexually transmitted diseases were not evaluated. Also, general and specific genotype distribution of HPV varies greatly among geographic areas, therefore, the current information cannot be extrapolated to substantial different settings.

\section{Abbreviations}

HPV: Human papillomavirus; Pap: Papanicolau; PCR: Polymerase chain reaction; DNA: Deoxyribonucleic acid; bp: Base pairs.

\section{Supplementary Information}

The online version contains supplementary material available at https://doi. org/10.1186/s13104-021-05588-7.

Additional file 1: Table S1. Human papillomavirus types and oncogenic potential. Table S2. Most frequent HPV types identified in the population studied.

\section{Acknowledgements}

We thank the staff of the health network from Hospital Regional Docente de Cajamarca, Peru.

\section{Authors' contributions}

JdVM, LJdV, WSC and MAAL designed the study protocol. JdVM, MAAL, CPR, CTV, YTC, and RAO performed the PCR. JdVM, LJdV, MAAL and WSC were responsible for obtaining funding and laboratory work supervision. LBG, LPV, CPR, HCN, RAO, ATM, YTC and CWSR were responsible for the clinical assessment, samples collection and database completion. JdVM, HCN, ATM and $\mathrm{LJdV}$ were responsible to draft the manuscript. All authors critically revised the manuscript for intellectual content. All authors read and approved the final manuscript.

\section{Funding}

This work was supported by Dirección de Investigación-Universidad Peruana de Ciencias Aplicadas. Grant Na C-012-2020-UPC, Lima-Peru.

\section{Availability of data and materials}

Abstraction format used in the study and dataset are available and accessible from the corresponding author upon request in the link: https://figshare. $\mathrm{com} / \mathrm{s} /$ f286fcb67120a72a7a07

\section{Declarations}

\section{Ethics approval and consent to participate}

This study was approved by the Research Ethics Board of the Hospital Regional de Cajamarca, Peru. The samples were obtained in the Specialized Oncological Preventive Service of the Hospital Regional de Cajamarca, as part of the cervical cancer screening program. The collection of the samples was done with a prior informed consent, which allowed the use of this samples for further studies.

\section{Consent for publication}

All authors have given their authorization for the publication of the manuscript.

\section{Competing interests}

On behalf of all authors, the corresponding author states that there are no conflicts of interest or funding related to this study.

\section{Author details}

${ }^{1}$ School of Medicine, Research and Innovation Center of the Faculty of Health Sciences, Universidad Peruana de Ciencias Aplicadas, Lima, Peru. ${ }^{2}$ Laboratorio de Biologia Molecular, Instituto de Investigación Nutricional, Lima, Peru. ${ }^{3} \mathrm{Hos}-$ pital Regional Docente de Cajamarca, Cajamarca, Peru. ${ }^{4}$ Escuela Profesional de Genética y Biotecnología. Facultad de Ciencias Biológicas, Universidad Nacional Mayor de San Marcos, Lima, Peru. ${ }^{5}$ Barcelona Research Center for Multiscale Science and Engineering, Departament D'Enginyeria Química, EEBE, Universitat Politècnica de Catalunya (UPC), Barcelona, Spain.

Received: 10 November 2020 Accepted: 28 April 2021

Published online: 07 May 2021

\section{References}

1. Chan CK, Aimagambetova G, Ukybassova T, Kongrtay K, Azizan A. Human papillomavirus infection and cervical cancer: epidemiology, screening, and vaccination-review of current perspectives. J Oncol. 2019;2019:3257939.

2. Crosbie EJ, Einstein MH, Franceschi S, Kitchener HC. Human papillomavirus and cervical cancer. Lancet. 2013;382(9895):889-99.

3. Brianti P, De Flammineis E, Mercuri SR. Review of HPV-related diseases and cancers. New Microbiol. 2017;40(2):80-5.

4. Bouvard V, Baan R, Straif K, Grosse Y, Secretan B, El Ghissassi F, et al. A review of human carcinogens - part B: biological agents. Lancet Oncol. 2009;10(4):321-2

5. Franceschi S, Herrero R, Clifford GM, et al. Variations in the age-specific curves of human papillomavirus prevalence in women worldwide. Int J Cancer. 2006;119(11):2677-84.

6. de Sanjosé S, Diaz M, Castellsagué $X$, et al. Worldwide prevalence and genotype distribution of cervical human papillomavirus DNA in women with normal cytology: a meta-analysis. Lancet Infect Dis. 2007;7(7):453-9.

7. Bray F, Ferlay J, Soerjomataram I, Siegel RL, Torre LA, Jemal A. Global cancer statistics 2018: GLOBOCAN estimates of incidence and mortality worldwide for 36 cancers in 185 countries. CA Cancer J Clin. 2018;68(6):394-424.

8. Sichero L, Picconi MA, Villa LL. The contribution of Latin American research to HPV epidemiology and natural history knowledge. Braz J Med Bio Res. 2020;53(2):e9560.

9. Paz-Soldán VA, Bayer AM, Nussbaum L, Cabrera L. Structural barriers to screening for and treatment of cervical cancer in Peru. Reprod Health Matters. 2012;20(40):49-58.

10. Aguilar A, Pinto JA, Araujo J, et al. Control of cervical cancer in Peru: current barriers and challenges for the future. Mol Clin Oncol. 2016;5(2):241-5. 
11. Coleman D. Limitations of the cervical smear test as a method of detecting women at risk of cervical cancer. Clin Risk. 2001;7(6):235-40.

12. Arbyn M, Weiderpass E, Bruni $L$, de Sanjosé $S$, Saraiya M, Ferlay J, et al. Estimates of incidence and mortality of cervical cancer in 2018: a worldwide analysis. Lancet Glob Health. 2020;8(2):e191-203.

13. Ronco G, Dillner J, Elfström K, Tunesi S, Snijders P, Arbyn M, et al. Efficacy of HPV-based screening for prevention of invasive cervical cancer: follow-up of four European randomised controlled trials. Lancet. 2014;383(9916):524-32

14. Wendland EM, Villa LL, Unger ER, et al. Prevalence of HPV infection among sexually active adolescents and young adults in Brazil: the POP-Brazil Study. Sci Rep. 2020;10(1):1-10.

15. Lurchachaiwong W, Junyangdikul P, Payungporn S, et al. Human papillomavirus genotypes among infected Thai women with different cytological findings by analysis of E1 genes. New Microbiol. 2011;34(2):147-56.

16. Wentzensen N, Schiffman M, Palmer T, Arbyn M. Triage of HPV positive women in cervical cancer screening. J Clin Virol. 2016;76:S49-55.

17. Arrossi S, Paolino M, Laudi R, et al. Programmatic human papillomavirus testing in cervical cancer prevention in the Jujuy Demonstration Project in Argentina: a population-based, before-and-after retrospective cohort study. Lancet Glob Health. 2019;7(6):e772-83.

18. Imai $\mathrm{H}$, Nakao $\mathrm{H}$, Shinohara $\mathrm{H}$, et al. Prevalence, potential predictors, and genotype-specific prevalence of human papillomavirus infection among sexually active students in Japan. PLoS ONE. 2015;10(7):e0132462.

19. Sabeena $S$, Bhat PV, Kamath $V$, et al. Community-based prevalence of genital human papilloma virus (HPV) infection: a systematic review and meta-analysis. Asian Pac J Cancer Prev. 2017;18(1):145-54.

20. Bruni L, Diaz M, Castellsagué X, Ferrer E, Bosch FX, de Sanjosé S. Cervical human papillomavirus prevalence in 5 continents: meta-analysis of 1 million women with normal cytological findings. J Infect Dis. 2010;202(12):1789-99.

21. Steben M, Duarte-Franco E. Human papillomavirus infection: epidemiology and pathophysiology. Gynecol Oncol. 2007;107(1):S2-5.

22. Vinodhini K, Shanmughapriya S, Das BC, Natarajaseenivasan K. Prevalence and risk factors of HPV infection among women from various provinces of the world. Arch Gynecol Obstet. 2012;285(3):771-7.

23. Castellsagué X, Drudis T, Cañadas MP, Goncé A, Ros R, Pérez JM, et al. Human Papillomavirus(HPV) infection in pregnant women and motherto-child transmission of genital HPV genotypes: a prospective study in Spain. BMC Infect Dis. 2019;9:74
24. Ricardo Martins T, Mendes C, Reis L, de Campos C, Regina CL, Villa LL, Levi JE. HPV genotype distribution in Brazilian women with and without cervical lesions: correlation to cytological data. Virol J. 2016;13:138.

25. Winer RL, Lee SK, Hughes JP, Adam DE, Kiviat NB, Koutsky LA. Genital human papillomavirus infection: rates and risk factors in a cohort of female university students. Am J Epidemiol. 2003;157:218-26.

26. Kjaer SK, Svare EI, Worm AM, Walboomers JM, Meijer CJ, van den Brule AJ. Human papillomavirus infection in Danish female sex workers: decreasing prevalence with age despite continuously high sexual activity. Sex Transm Dis. 2000;27:438-45.

27. Lam JU, Rebolj M, Dugué PA, Bonde J, von Euler-Chelpin M, Lynge E. Condom use in prevention of human papillomavirus infections and cervical noeplasia: systematic review of longitudinal studies. J Med Screen. 2014;21(1):38-50.

28. Anderson TA, Schick V, Herbenick D, Dodge B, Fortenberry JD. A study of human papillomavirus on vaginally inserted sex toys, before and after cleaning, among women who have sex with women and men. Sex Transm Infect. 2014;90(7):529-31.

29. American College of Obstetricians and Gynecologist. Committee on Practice Bulletins-Gynecology. Practice Bulletin No. 168: cervical cancer screening and prevention. Obstet Gynecol. 2016;128(4):e111-30.

30. American cancer Society. American society for Colposcopy and Cervical Pathology, and American Society for Clinical Pathology screening guidelines for the prevention and earyl detection of cercal cancer. CA Cancer J clin. 2012;62(3):147-72.

31. Moyer VA. Screening for cervical cancer: U.S. Preventive Services Task Force recommendation statement. Ann Intern Med. 2012; 156(12): 880-91, W312.

32. Cibula D, Potter R, Planchamp F, Avall-Lundqvist E, Fischerova D, Haie Meder C, et al. The European Society of Gynaecological Oncology/ European Society for Radiotherapy and Oncology/ European Society of Pathology guidelines for the management of patients with cervical cancer. Rdiother Oncol. 2018;127(3):404-16.

\section{Publisher's Note}

Springer Nature remains neutral with regard to jurisdictional claims in published maps and institutional affiliations.
Ready to submit your research? Choose BMC and benefit from:

- fast, convenient online submission

- thorough peer review by experienced researchers in your field

- rapid publication on acceptance

- support for research data, including large and complex data types

- gold Open Access which fosters wider collaboration and increased citations

- maximum visibility for your research: over $100 \mathrm{M}$ website views per year

At BMC, research is always in progress.

Learn more biomedcentral.com/submissions 